\title{
Epidemiological Aspect of Burnout among Careful Staff of a Zone Hospital in Cotonou in 2019
}

\section{Rose Mikponhoue $^{1^{*}}{ }^{\circledR}$, Antoine Hinson ${ }^{1}$ (), Mênonli Adjobimey ${ }^{1}{ }^{(0)}$, Patrick Sembeya1, Ibrahim Mama Cisse ${ }^{2}{ }^{(1)}$, Fabien Gounongbe ${ }^{2}$, Paul Ayelo ${ }^{1}$}

\author{
${ }^{1}$ Faculty of Health Sciences, Research Unit in Occupational Health and Environment, Cotonou, Benin \\ ${ }^{2}$ Departemental Teaching Hospital of Borgou, Parakou, Benin \\ Email: *nayetoon@yahoo.fr
}

How to cite this paper: Mikponhoue, R., Hinson, A., Adjobimey, M., Sembeya, P., Cisse, I.M., Gounongbe, F. and Ayelo, P. (2021) Epidemiological Aspect of Burnout among Careful Staff of a Zone Hospital in Cotonou in 2019. Occupational Diseases and Environmental Medicine, 9, 49-62.

https://doi.org/10.4236/odem.2021.92005

Received: January 27, 2021

Accepted: May 22, 2021

Published: May 25, 2021

Copyright $\odot 2021$ by author(s) and Scientific Research Publishing Inc. This work is licensed under the Creative Commons Attribution International License (CC BY 4.0).

http://creativecommons.org/licenses/by/4.0/

\begin{abstract}
Introduction: Burnout syndrome is one of the many forms of suffering at work that affects healthcare professionals. It is still little diagnosed in Benin. Objectives: the objective was to assess the prevalence of burnout among the nursing staff of a Zone Hospital (HZ) in Cotonou. Study Methods: This was a descriptive and analytical cross-sectional study, which took place from September to October 2019 and included all personnel assigned to care. This has been submitted to the Malasch Burnout Inventory (MBI). The data collected was analyzed using STATA software version 15. A logistic regression made it possible to identify those associated with burnout. The significance level was 5\%. Result: A total of 173 caregivers were included, including 118 women, for a sex ratio of 0.47 . The mean age was $39 \pm 10.1$ years. The study population consisted of $33.5 \%$ nursing assistants, $24.3 \%$ nurses, $24.2 \%$ physicians, $7.5 \%$ midwives, and $8.6 \%$ other health professionals. The prevalence of burnout was $30.6 \%$ of which $2.3 \%$ were severe cases. As a result of burnout, $33 \%$ of officers and $19.08 \%$ experienced depersonalization and $10.4 \%$ experienced a sense of low personal achievement. The associated factors identified were female sex ( $\mathrm{p}<0.0001)$, lack of time devoted to her family $(\mathrm{p}=0.04)$, receiving negative remarks on this lack of availability towards her family $(\mathrm{p}=0.04)$, and work in a poor professional climate $(\mathrm{p}=0.03)$. Conclusion: the prevalence of burnout among caregivers is high. Improving the professional climate and family relations are avenues for prevention.
\end{abstract}

\section{Keywords}

Burnout, Nursing Staff, Epidemiology, Benin 


\section{Introduction}

Burnout is a long and evolving phenomenon that occurs after years of prolonged exposure to professional stress [1]. It is mainly health-related professions that are prone to be very affected by this pathology [2]. Indeed, health workers are engaged in a daily helping relationship with others and are subject to chronic occupational stress; they are likely to suffer from burnout syndrome. The consequences can range from reduced work performance to, in more serious cases, a more or less prolonged work stoppage or even the resignation of the health worker [3]. In Europe, $12 \%$ of nurses and 17\% of doctors were at risk of burnout and $6 \%$ of nurses versus $5 \%$ of doctors had severe burnout in a study in Belgium [4]. In Africa, the prevalence of burnout is $42.4 \%$ among general practitioners in the city of Douala in Cameroon [5]. Among Malagasy doctors, its prevalence has been estimated at $51.2 \%$ with $4.2 \%$ of severe forms [6]. In Benin, difficult working conditions such as insufficient technical facilities, late recourse to care for patients or referrals in precarious situations, and the low remuneration of health care personnel are multiple factors of emotional exhaustion and demotivation of health care professionals. They are therefore highly exposed to burnout, which, despite the abundant international literature, remains an under-diagnosed disease in our country. The objectives of this study are to determine the prevalence and factors associated with burnout in the caregivers of a Zone Hospital (HZ) in Cotonou.

\section{Framework and Methods of Study}

This is a descriptive and analytical cross-sectional study that took place from September 9 to October 8, 2019 in an HZ of the city of Cotonou. It is the referral hospital for health zone V. It concentrates about $40 \%$ of the health activities of the entire zone. The daily flow of patients is important. The nursing staff is sometimes overwhelmed by the workload. Also, some complaints have been recorded from hospital users. They were related to long waiting lines and sometimes to certain services considered of poor quality. This study was initiated to assess the working conditions of the caregivers.

The hospital employs a total of 236 workers, including 41 administrative staff. Non-probability convenience sampling was conducted by exhaustive recruitment of workers meeting the following criteria:

- have an employment contract

- be medical or paramedical personnel

- consent to participate in the study.

The data collection was carried out using a questionnaire. It is the validated Malash Burnout Inventory (MBI) questionnaire that explores the three dimensions of emotional exhaustion, depersonalization and personal accomplishment. This scale is composed of 22 items, each rated from 0 to 6 [7].

- Emotional exhaustion is assessed by nine items for a total of 0 to 54, a score of 30 or more being considered high;

- Depersonalization is assessed by five items for a total of 0 to 30 , with a score 
greater than or equal to 12 considered high;

- Professional achievement is rated by eight items $(4,7,9,12,17,18,19$, and 21) for a total of 0 to 48 , with a score less than or equal to 33 considered low [7].

Data analysis was conducted using STATA version 15.0 software. The chi-2 test allowed a comparison of the variables. Univariate logistic regression was used to look for factors related to burnout syndrome. All tests were interpreted with a significance threshold of $5 \%$.

Authorization from hospital officials was taken as well as informed consent from each participant.

\section{Results}

A total of 195 agents were regularly assigned to care. Of these, 176 consented to participate in the study, but three survey forms were not usable. Sociodemographic characteristics of the agents, 173 caregivers participated in this study, which is a participation rate of $88.71 \%$.

- Socio-demographic characteristics of agents

Of the 173 caregivers making up the sample size, 118 (68\%) were female, for a sex ratio $(\mathrm{M} / \mathrm{F})$ of 0.47 . The sample size is based on a sample of 173 caregivers, of which $118(68 \%)$ were female. The mean age was $39 \pm 10.1$ years with extremes of 21 and 60 years. Half of them were married with an average of two dependent children. Also, $63 \%$ of caregivers did not spend enough time with their family and $60.7 \%$ received negative comments from family and friends about their lack of availability. These data are summarized in Table 1.

- Caregiver Job Characteristics

Doctors and nurses represented $48.6 \%$ of the population; and health care aides, $33.5 \%$. The average seniority was $6 \pm 9.6$ years. Almost all 3/4 (71.6\%) worked more than 40 hours per week; and 33\% felt that the work climate was poor. Table 2 presents the occupational characteristics of caregivers.

- Caregiver Lifestyle

Outside of work hours, $24.9 \%$ practiced a regular sport activity. Alcohol and psychotropic drugs were consumed by $32.4 \%$ and $17.9 \%$ of the carers. Table 3 describes the lifestyle habits of the carers surveyed.

- Prevalence of burnout

The prevalence of burnout is $30.6 \%$, of which $22 \%$ is low burnout, $6.3 \%$ medium severity and $2.3 \%$ severe burnout. In addition, $19.08 \%$ of the caregivers had a high state of emotional exhaustion; $12.14 \%$ had a high degree of depersonalization and $10.4 \%$ a low sense of emotional fulfillment. These data are presented in Table 4.

- Factors associated with burnout among caregivers at a Zone Hospital in Cotonou Female caregivers suffered more burnout than male caregivers $(\mathrm{P}<0.0001)$; so did those who spent little time with their families and received negative criticism from them about this lack of availability $(p=0.04)$. In addition, a poor work climate favored burnout $(\mathrm{p}=0.03)$. Table 5 summarizes the factors associated 
Table 1. Socio-demographic characteristics of caregivers at a zone hospital in Cotonou in 2019.

\begin{tabular}{|c|c|c|}
\hline Characteristics & Effective (n) & Pourcentage (\%) \\
\hline \multicolumn{3}{|l|}{ Age (ans) } \\
\hline$<30$ & 39 & 22.5 \\
\hline $30-40$ & 48 & 27.7 \\
\hline $41-49$ & 51 & 29.5 \\
\hline$\geq 50$ & 35 & 20.2 \\
\hline \multicolumn{3}{|l|}{ Gender } \\
\hline Male & 55 & 32.0 \\
\hline Female & 118 & 68.0 \\
\hline \multicolumn{3}{|l|}{ Marital status } \\
\hline married & 93 & 53.8 \\
\hline Single & 48 & 27.7 \\
\hline Cohabitation & 29 & 16.8 \\
\hline Widow/er & 2 & 01.2 \\
\hline Divorced & 1 & 0.6 \\
\hline \multicolumn{3}{|c|}{ Nomber of dependent children } \\
\hline No & 39 & 22.5 \\
\hline$[1-3]$ & 104 & 60.1 \\
\hline$[4-6]$ & 27 & 15.6 \\
\hline$\geq 7$ & 3 & 01.7 \\
\hline \multicolumn{3}{|c|}{ Time spent with family } \\
\hline Yes & 64 & 37.0 \\
\hline No & 109 & 63.0 \\
\hline \multicolumn{3}{|c|}{ Negative remarks on availability towards the family } \\
\hline Yes & 105 & 60.7 \\
\hline No & 68 & 39.3 \\
\hline
\end{tabular}

Table 2. Occupational characteristics of caregivers at HZ in Cotonou in 2019.

\begin{tabular}{ccc}
\hline Variables & Effective (n) & Pourcentage (\%) \\
\hline Professional categories & 58 & \\
Caregivers & 42 & 33.5 \\
Nurses & 42 & 24.3 \\
Physicians & 13 & 24.3 \\
Midwives & 3 & 07.5 \\
Physiotherapists & 15 & 01.7 \\
Others & & 08.6 \\
\hline
\end{tabular}




\section{Continued}

Seniority (years)

$\begin{array}{ccc}<1 & 12 & 06.9 \\ 1-10 & 79 & 45.7 \\ 10-20 & 42 & 24.3 \\ >20 & 40 & 23.1\end{array}$

Number of shifts per month

$\begin{array}{ccc}00 & 71 & 41.0 \\ 1-6 & 17 & 09.8 \\ 6-11 & 78 & 45.1 \\ >11 & 7 & 04.0\end{array}$

Number of working hours

$\begin{array}{ccc}<40 & 49 & 28.3 \\ {[40-72[} & 107 & 61.8 \\ \geq 72 & 17 & 09.8\end{array}$

Work climate

$\begin{array}{ccc}\text { Very good } & 23 & 13.0 \\ \text { Good } & 112 & 65.0 \\ \text { Bad } & 33 & 19.0 \\ \text { Very bad } & 5 & 03.0\end{array}$

Social worker (1); PMCT mediator (1); Pharmacist (1); Psychological counselor (1); Biotechnologists (1); Medical Imaging Engineers (1).

Table 3. Distribution of caregivers according to their lifestyles.

\begin{tabular}{ccc}
\hline Variable & Effective (n) & Pourcentage (\%) \\
\hline Alcohol consumption & 56 & 32.4 \\
Yes & 117 & 67.6 \\
No & & \\
Use of psychotropic drugs & 31 & 17.9 \\
Yes & 142 & 82.1 \\
No & & \\
Sports and leisure activities & & 24.9 \\
Regular sport activity & 43 & 75.1 \\
Yes & 130 & \\
No & & 30.1 \\
Regular Leisure & 52 & 69.9 \\
Yes & 121 &
\end{tabular}


Table 4. Prevalence of burnout and its dimensions among caregivers in a Zone Hospital in Cotonou in 2019.

\begin{tabular}{cccc}
\hline Variable & & Effective (n) & Pourcentage (\%) \\
\hline No burnout & & 120 & 69.4 \\
\hline \multirow{2}{*}{ Présence of burnout } & low & 38 & 22.0 \\
& Moderate & 11 & 6.3 \\
& Severe & 4 & 2.3 \\
\hline High emotional exhaustion & 53 & 30.6 \\
\hline High depersonalization & Total & 33 & 19.08 \\
\hline Low personal achievement & 21 & 12.14 \\
\hline
\end{tabular}

Table 5. Factors associated with burnout among caregivers at a Zone Hospital in Cotonou in 2019.

\begin{tabular}{|c|c|c|c|c|c|}
\hline \multirow{3}{*}{ Variables } & \multicolumn{4}{|c|}{ Burnout } & \multirow{3}{*}{$\mathrm{p}$} \\
\hline & \multirow{2}{*}{\multicolumn{2}{|c|}{$\begin{array}{l}\text { Yes } \\
\mathrm{n} \%\end{array}$}} & \multicolumn{2}{|c|}{ No } & \\
\hline & & & \multicolumn{2}{|c|}{$\mathrm{n} \%$} & \\
\hline \multicolumn{6}{|l|}{ Gender } \\
\hline Male & 9 & 16.4 & 46 & 83.6 & $<0.0001$ \\
\hline Female & 44 & 37.3 & 74 & 62.7 & \\
\hline \multicolumn{6}{|l|}{ Age } \\
\hline$[21-30]$ & 9 & 23.1 & 30 & 76.9 & 0.42 \\
\hline$[30-40]$ & 17 & 35.4 & 31 & 64.6 & \\
\hline$[40-50]$ & 19 & 37.3 & 32 & 62.7 & \\
\hline$[50-60]$ & 8 & 22.9 & 27 & 77.1 & \\
\hline \multicolumn{6}{|l|}{ Seniority } \\
\hline$<1$ year & 5 & 41.7 & 7 & 58.3 & 0.68 \\
\hline$\geq 1$ year & 48 & 28.57 & 120 & 71.42 & \\
\hline \multicolumn{6}{|c|}{ Occupational Category } \\
\hline Nurse & 16 & 38.1 & 26 & 61.9 & 0.52 \\
\hline Midwide & 6 & 46.2 & 7 & 53.8 & \\
\hline Physician & 10 & 27.0 & 27 & 73.0 & \\
\hline Surgeon & 1 & 20.0 & 4 & 80.0 & 0.58 \\
\hline Caregivers & 15 & 25.9 & 43 & 74.1 & \\
\hline Other & 5 & 27.8 & 13 & 72.2 & \\
\hline \multicolumn{6}{|c|}{ Alcohol consumption and psychotropic drugs } \\
\hline Yes & 10 & 32.26 & 21 & 67.74 & 0.82 \\
\hline No & 43 & 30.28 & 94 & 69.72 & \\
\hline
\end{tabular}




\section{Continued}

Practice of a sports/leisure activity

\begin{tabular}{|c|c|c|c|c|c|}
\hline Yes & 9 & 20.93 & 34 & 79.07 & 0.11 \\
\hline No & 44 & 33.84 & 86 & 66.16 & \\
\hline \multicolumn{6}{|c|}{ Hours of work/week } \\
\hline$<40 \mathrm{~h}$ & 17 & 34.7 & 32 & 65.3 & \multirow{3}{*}{0.76} \\
\hline$[40-72]$ & 31 & 29.0 & 76 & 71.0 & \\
\hline$\geq 72 \mathrm{~h}$ & 5 & 29.4 & 12 & 70.6 & \\
\hline \multicolumn{6}{|c|}{ Time spent with family } \\
\hline Yes & 14 & 21.88 & 50 & 78.12 & \multirow[t]{2}{*}{0.04} \\
\hline No & 39 & 35.78 & 70 & 64.22 & \\
\hline \multicolumn{6}{|c|}{ Criticisms on the lack of availability } \\
\hline Yes & 35 & 33.33 & 70 & 66.67 & \multirow[t]{2}{*}{0.04} \\
\hline No & 18 & 26.47 & 50 & 73.53 & \\
\hline \multicolumn{6}{|c|}{ Work climate } \\
\hline Very good & 3 & 13.6 & 19 & 86.4 & \multirow{4}{*}{0.03} \\
\hline Good & 35 & 31.3 & 77 & 68.8 & \\
\hline $\mathrm{Bad}$ & 11 & 32.4 & 23 & 67.6 & \\
\hline Very bad & 4 & 80.0 & 1.0 & 20.0 & \\
\hline
\end{tabular}

with burnout among caregivers.

- Factors associated with dimensions of burnout in caregivers

Women were 1.8 times more likely to experience low personal fulfillment $(\mathrm{p}=$ $0.01 \mathrm{OR}=1.8[1.1 ; 2.9])$. Caregivers who received negative criticism from family for not being available were more likely to have low self-actualization $(\mathrm{p}=0.03$; $\mathrm{OR}=1.1[0.7 ; 1.7])$. Good work climate protected against low personal accomplishment $(\mathrm{p}<0.0001 ; 0.5[0.3 ; 0.9])$. Women were 1.9 times more likely to experience emotional exhaustion than men $(\mathrm{p}=0.003$; $\mathrm{OR}=1.9[1.2 ; 2.9])$. Caregivers with less than one year of work experience were three times more likely to experience emotional exhaustion $(\mathrm{p}=0.009$; $\mathrm{OR}=2.8[1.2 ; 6.2])$. Working in a good work climate protects against the occurrence of emotional exhaustion by two times $(\mathrm{p}<0.0001 ; \mathrm{OR}=0.5[0.3 ; 0.7])$. Working in a poor climate and consuming alcohol were sources of depersonalization among caregivers $(\mathrm{p}=0.021$ and $\mathrm{OR}=0.5$ and 0.6 , respectively). The factors associated with the dimensions of burnout are summarized in Table 6 .

\section{Discussion}

The objective of our study was to determine the prevalence of burnout and factors associated with it among caregivers in an area hospital. The high participation rate and the use of a validated questionnaire for data collection are a strength of the study. However, the subjectivity of the responses could introduce 
Table 6. Factors associated with the dimensions of burnout among caregivers at a Zone Hospital in Cotonou in 2019.

\begin{tabular}{|c|c|c|c|c|c|c|c|c|c|c|c|c|c|c|c|c|}
\hline \multirow{2}{*}{\multicolumn{2}{|c|}{$\begin{array}{l}\text { Factors associated } \\
\text { with burnout } \\
\text { dimensions }\end{array}$}} & \multicolumn{5}{|c|}{ Emotional exhaustion } & \multicolumn{5}{|c|}{ Depersonnalization } & \multicolumn{5}{|c|}{ Low personal achievement } \\
\hline & & Low & medium & High & $\mathrm{p}$ & $\mathrm{OR}\left[\mathrm{IC}_{95}\right]$ & Low & Medium & High & $\mathrm{p}$ & $\mathrm{OR}\left[\mathrm{IC}_{95}\right]$ & Low & Medium & High & $\mathrm{p}$ & $\mathrm{OR}\left[\mathrm{IC}_{95}\right]$ \\
\hline \multirow{2}{*}{ Gender } & Male & 30 & 20 & 5 & \multirow{2}{*}{0.003} & & 33 & 13 & 5 & \multirow{2}{*}{$n s^{*}$} & & 3 & 6 & 46 & \multirow{2}{*}{0.01} & \\
\hline & Female & 40 & 50 & 28 & & $1.9[1.2 ; 2.9]$ & 67 & 36 & 16 & & $1.1[0.7 ; 1.7]$ & 15 & 29 & 74 & & $1.8[1.1 ; 2.9]$ \\
\hline \multirow{2}{*}{ Age (Year) } & $<50$ & 57 & 52 & 29 & \multirow{2}{*}{$\mathrm{ns}^{*}$} & $1.3[0.7 ; 2.2]$ & 76 & 44 & 21 & \multirow{2}{*}{$\mathrm{ns}^{*}$} & $1.4[0.8 ; 2.4]$ & 15 & 29 & 93 & \multirow{2}{*}{$\mathrm{ns}^{*}$} & $1.3[0.7 ; 2.2]$ \\
\hline & $\geq 50$ & 13 & 18 & 4 & & & 24 & 8 & 3 & & & 3 & 5 & 27 & & \\
\hline \multirow{2}{*}{$\begin{array}{l}\text { Professional } \\
\text { experience }\end{array}$} & $<1$ & 60 & 69 & 32 & \multirow{2}{*}{0.009} & $2.8[1.2 ; 6.2]$ & 92 & 51 & 19 & \multirow{2}{*}{$\mathrm{ns}^{*}$} & $1.4[0.8 ; 2.4]$ & 16 & 31 & 114 & \multirow{2}{*}{$\mathrm{ns}^{*}$} & $0.5[0.2 ; 1.3]$ \\
\hline & $\geq 1$ & 10 & 1 & 1 & & & 8 & 1 & 3 & & & 2 & 4 & 6 & & \\
\hline \multirow{2}{*}{$\begin{array}{l}\text { Time spent } \\
\text { with family }\end{array}$} & Yes & 32 & 24 & 8 & \multirow{2}{*}{0.03} & & 44 & 15 & 5 & \multirow{2}{*}{0.03} & & 3 & 13 & 48 & \multirow{2}{*}{$\mathrm{ns}^{*}$} & \\
\hline & No & 38 & 46 & 25 & & $1.5[1.0 ; 2.4]$ & 56 & 37 & 16 & & $1.5[1.0 ; 2.5]$ & 15 & 22 & 72 & & $1.4[0.9 ; 2.3]$ \\
\hline \multirow{2}{*}{$\begin{array}{l}\text { Negative } \\
\text { remarks }\end{array}$} & Yes & 36 & 45 & 24 & \multirow{2}{*}{0.03} & $1.5[1.0 ; 2.3]$ & 53 & 37 & 15 & \multirow{2}{*}{0.03} & $1.5[1.0 ; 2.5]$ & 13 & 19 & 73 & \multirow{2}{*}{0.03} & $1.1[0.7 ; 1.7]$ \\
\hline & No & 34 & 25 & 9 & & & 47 & 15 & 6 & & & 5 & 16 & 47 & & \\
\hline \multirow{2}{*}{$\begin{array}{l}\text { Climat } \\
\text { de travail }\end{array}$} & Good & 64 & 48 & 22 & \multirow[b]{2}{*}{$<0.0001$} & $0.5[0.3 ; 0.7]$ & 82 & 35 & 16 & \multirow{2}{*}{0.021} & $0.5[0.4 ; 1.2]$ & 11 & 25 & 98 & \multirow[b]{2}{*}{$<0.0001$} & $0.5[0.3 ; 0.9]$ \\
\hline & $\mathrm{Bad}$ & 6 & 22 & 11 & & & 18 & 16 & 5 & & & 7 & 10 & 22 & & \\
\hline \multirow{2}{*}{$\begin{array}{c}\text { Alcohol } \\
\text { comsumption }\end{array}$} & Yes & 19 & 25 & 12 & \multirow{2}{*}{$n s^{*}$} & & 27 & 18 & 11 & \multirow{2}{*}{0.021} & & 7 & 12 & 37 & & \\
\hline & No & 51 & 45 & 21 & & $0.8[0.5 ; 1.2]$ & 73 & 34 & 10 & & $0.6[0.3 ; 0.9]$ & 11 & 23 & 83 & $\mathrm{~ns}^{*}$ & $0.8[0.5 ; 1.3]$ \\
\hline
\end{tabular}

*Not significative.

bias with respect to the true prevalence of burnout among caregivers. Furthermore, the cross-sectional nature of the study does not allow us to formally establish causal links between the different variables.

The prevalence of burnout was $30.6 \%$ among caregivers in our study. It is comparable to the $39.9 \%$ obtained by Navarro-Gonzalez et al. among health professionals in Navarra, Spain [8], but higher than the $17.2 \%$ and $18.3 \%$ found among primary care nurses in Barcelona, Spain and Brazil [9] [10], and much lower than the $63 \%, 68.3 \%$ and $70 \%$ found respectively in the Yaoundé central hospital in Cameroon, in a university hospital in the north of Benin, and Tunisian units taking care of patients at the end of life [11] [12] [13]. Note that low prevalences are obtained in primary care units, perhaps because the workload is not comparable to that in specialized hospitals where complex cases are referred. On the other hand, low prevalences have also been found in countries such as Holland, Colombia, and the USA, with 18, 19.2\%, and $20 \%$ of burnout respectively among caregivers, although these studies were carried out in intensive care units [14] [15] [16]. These differences can also be explained by the performance of the health care systems in these countries, which allow for optimal patient care, thus reducing the personal efforts of health care professionals and creating better working conditions.

Several factors have been identified in the literature as being associated with the occurrence of burnout among healthcare professionals. In our study, female caregivers appeared to be more affected $(\mathrm{p}<0.001)$; they were more emotionally 
exhausted $(p=0.003)$ and had a lower sense of personal achievement $(p=0.001)$ than male caregivers. This may be related to the overload of work related to the combination of professional activity and household tasks that are usually culturally assigned to women in our society. While our results agree with those of some authors in Saudi Arabia and Brazil, the literature on this subject is mixed, Indeed, in other countries such as Ethiopia, Tunisia, and Spain, it was men who seemed to be more affected by burnout [8] [13] [17] [18] [19]; on the other hand, in the study of Neugeu et al. in Cameroon, gender had no influence on the occurrence of burnout [11].

Young professional experience is correlated with emotional exhaustion $(\mathrm{p}=$ 0.009) but not with the other dimensions of burnout. Indeed, one could think that young caregivers, having only recently started their activity, do not yet have the necessary professional experience to cope with stressful situations. Our data are consistent with those of Bhagavathula et al. in Ethiopia [17] but differ from those of Merces et al. and Piava et al. in two different studies in Brazil [10] [19].

Working in a bad work environment is a source of burnout. Caregivers who work in a poor work climate have significantly higher emotional exhaustion and depersonalization scores than other caregivers $(\mathrm{p}=0.012$ and $\mathrm{p}<0.001)$. The latter also has a significantly lower self-actualization score compared with other caregivers $(p=0.007)$. Several authors have emphasized the importance of quality of work life in the occurrence of burnout [20] [21]. Mion et al. made the same observation by finding a link between all dimensions of burnout and conflicts at work $(\mathrm{p}<0.00001)$ in several Anesthesia-Resuscitation facilities in Metropolitan France [22].

Suffering at work can not only have a negative impact on the provision of care but also on family relationships. Indeed, according to our results, those who devoted little time to their family and received negative remarks about their lack of availability were more exposed to burnout $(\mathrm{p}=0.04)$, presented emotional exhaustion $(\mathrm{p}=0.012)$ and feelings of depersonalization $(\mathrm{p}=0.039)$. Our results corroborate those of Neugeu et al. in Cameroon, Adelin et al. in Parakou, and Jalili et al. in Iran [11] [12] [23]. This could be explained by the fact that the family provides a refuge for the caregiver to draw on the resources needed to cope with the various stressful demands of his/her work. And the difficulties in reconciling family and professional life could only contribute to the stress felt. These results show the need for the caregiver to be supported by his family circle in order to be more fulfilled professionally.

As far as lifestyle habits are concerned, while regular sports and leisure activities had no impact on the occurrence of burnout, alcohol consumption is a source of depersonalisation $(\mathrm{p}=0.021)$. Our data contradict those of other authors with regard to the practice of a sporting activity [10] [24]. Indeed, sport could be an important source of relaxation and be beneficial to the caregiver; he would learn to better manage the stress he feels. As for alcohol consumption, it could seem to be a temporary solution for the stressed carer to relax; this is only 
an illusion because the phenomenon of dependency can quickly take hold, which would only contribute to deterioration in the carer's state of health.

\section{Conclusion}

This study shows a high prevalence of burnout among caregivers at the Zone Hospital in Cotonou. It shows that the factors of burnout are not only professional; the private life of the caregiver also has an impact on the occurrence of this pathology. It is, therefore, necessary for the caregiver to reconcile his or her family and professional life to maintain a stable psychological state and a better performance at work.

\section{Conflicts of Interest}

The authors declare no conflicts of interest regarding the publication of this paper.

\section{References}

[1] Boudarene, M. (2004) Souffrance au travail et Burn out chez des agents de Police en exercice. Une étude préliminaire. Souffrance au travail et Burn out chez des agents de Police en exercice. Une étude préliminaire, 6, 2.

[2] Freudenberger, H.J. (1975) The Staff Burn-Out Syndrome in Alternative Institutions. Psychotherapy: Theory, Research \& Practice, 12, 73-82.

https://doi.org/10.1037/h0086411

[3] Guéritault-Chalvin, V. and Cooper, C. (2004) Mieux comprendre le burnout professionnel et les nouvelles stratégies de prévention: Un compte rendu de la littérature. Journal de Thérapie Comportementale et Cognitive, 14, 59-70. https://doi.org/10.1016/S1155-1704(04)97446-0

[4] Vandenbroeck, S., Van Gerven, E., De Witte, H., Vanhaecht, K. and Godderis, L. (2017) Burnout in Belgian Physicians and Nurses. Occupational Medicine, 67, 546-554. https://doi.org/10.1093/occmed/kqx126

[5] Moueleu Ngalagou, P.T., Assomo Ndemba, P.B., Owona Manga, L.J., Bandga Ekanga, Y., Guessogo, W.R., Ayina Ayina C.N., et al. (2018) Syndrome du burnout chez le personnel soignant paramédical au Cameroun: impact des activités physiques et sportives et des loisirs. Archives des Maladies Professionnelles et de P Environnement, 79, 55-63. https://doi.org/10.1016/j.admp.2017.10.006

[6] Rakotondrainibe, A., Randriamizao, H.M.R., Ratsimbazafy, N.S., Mong-Gine, Y., Rakotoarison, C.N., Rakototiana, F.A., et al. (2018) Burnout syndrome et ses facteurs chez les médecins de deux centres Hospitalo-Universitaires d'Antananarivo. Pan African Medical Journal, 31, Article No. 63. https://doi.org/10.11604/pamj.2018.31.63.11123

[7] Maslach, C. and Jackson, S.E. (1981) The Measurement of Experienced Burnout. Journal of Organizational Behavior, 2, 99-113. https://doi.org/10.1002/job.4030020205

[8] Navarro-González, D., Ayechu-Díaz, A. and Huarte-Labiano, I. (2015) Prevalence of Burnout Syndrome and Its Associated Factors in Primary Care Staff. SEMERGENMedicina de Familia, 41, 191-198. https://doi.org/10.1016/j.semerg.2014.03.008

[9] Vilà Falgueras, M., Cruzate Muñoz, C., Orfila Pernas, F., Creixell Sureda, J., González López, M.P. and Davins Miralles, J. (2015) Burnout y trabajo en equipo en 
los profesionales de Atención Primaria. Atención Primaria, 47, 25-31. https://doi.org/10.1016/j.aprim.2014.01.008

[10] Merces, M.C., Coelho, J.M.F., Lua, I., Silva, D., Gomes, A.M.T., Erdmann, A.L., et al. (2020) Prevalence and Factors Associated with Burnout Syndrome among Primary Health Care Nursing Professionals: A Cross-Sectional Study. International Journal of Environmental Research and Public Health, 17, Article No. 474. https://doi.org/10.3390/ijerph17020474

[11] Negueu, A.B., Cumber, S.N., Donatus, L., Nkfusai, C.N., Ewang, B.F., Bede, F., et al. (2019) Burnout chez les professionnels soignants de l'Hôpital Central de Yaoundé. Pan African Medical Journal, 34, Article No. 126. https://doi.org/10.11604/pamj.2019.34.126.19969

[12] Adelin,T.,B., Anselme., D., Frédéric, T.N.C., Armistice, G.G.T. and Prosper, G. (2018) Burn-Out Chez Le Personnel Soignant Des Unités De Soins Intensifs De L'hôpital Universitaire De Parakou Au Bénin. European Scientific Journal, 14, 408-421. https://doi.org/10.19044/esj.2018.v14n24p408

[13] Amamou, B., Bannour, A.S., Hadj, M.B., Nasr, S.B. and Hadj Ali, B.B. (2014) Haute prévalence du Burnout dans les unités Tunisiennes prenant en charge des patients en fin de vie. Pan African Medical Journal, 19, Article No. 9. https://doi.org/10.11604/pamj.2014.19.9.2865

[14] Van der Wal, R.A.B., Bucx, M.J.L., Hendriks, J.C.M., Scheffer, G.J. and Prins, J.B. (2016) Psychological Distress, Burnout and Personality Traits in Dutch Anaesthesiologists: A Survey. European Journal of Anaesthesiology, 33, 179-186. https://doi.org/10.1097/EJA.0000000000000375

[15] Eslava-Schmalbach, J., Garzón-Orjuela, N., Martínez, N.T., Gonzalez-Gordon, L., Rosero, E. and Gómez-Restrepo, C. (2020) Prevalence and Factors Associated with Burnout Syndrome in Colombian Anesthesiologists. International Journal of Preventive Medicine, 11, Article No. 5.

[16] De Oliveira, G.S., Almeida, M.D., Ahmad, S., Fitzgerald, P.C. and McCarthy, R.J. (2011) Anesthesiology Residency Program Director Burnout. Journal of Clinical Anesthesia, 23, 176-182. https://doi.org/10.1016/j.jclinane.2011.02.001

[17] Bhagavathula, A.S., Abegaz, T.M., Belachew, S.A., Gebreyohannes, E.A., Gebresillassie, B.M., Chattu, V.K., et al. (2018) Prevalence of Burnout Syndrome among Health-Care Professionals Working at Gondar University Hospital, Ethiopia. Journal of Education and Health Promotion, 7, Article No. 145.

[18] Alqahtani, A.M., Awadalla, N.J., Alsaleem, S.A., Alsamghan, A.S. and Alsaleem, M.A. (2019) Burnout Syndrome among Emergency Physicians and Nurses in Abha and Khamis Mushait Cities, Aseer Region, Southwestern Saudi Arabia. Scientific World Journal, 2019, Article ID: 4515972. https://doi.org/10.1155/2019/4515972

[19] Paiva, L., Canário, A., China, E. and Gonçalves, A. (2017) Burnout Syndrome in Health-Care Professionals in a University Hospital. Clinics, 72, 305-309. https://doi.org/10.6061/clinics/2017(05)08

[20] Kharraz, O.E. and Nasser, H. (2017) La qualité de vie au travail dans le milieu hospitalier: Cas des hôpitaux tangérois. Dossiers de Recherches en Économie et Gestion, 6, 91-120.

[21] McGillis Hall, L., Doran, D., Baker, G.R., Pink, G.H., Sidani, S., O’Brien-Pallas, L., et al. (2003) Nurse Staffing Models as Predictors of Patient Outcomes. Medical Care, 41, 1096-10109. https://doi.org/10.1097/01.MLR.0000084180.07121.2B

[22] Mion, G., Libert, N. and Journois. D. (2013) Facteurs associés au burnout en anesthésie-réanimation. Enquête 2009 de la Société française d'anesthésie et de 
réanimation. Annales Françaises d Anesthésie et de Réanimation, 32, 175-188.

https://doi.org/10.1016/j.annfar.2012.12.004

[23] Jalili, M., Sadeghipour Roodsari, G. and Bassir Nia, A. (2013) Burnout and Associated Factors among Iranian Emergency Medicine Practitioners. Iranian Journal of Public Health, 42, 1034-1042.

[24] Tsai, H.H., Yeh, C.Y., Su, C.T., Chen, C.J., Peng, S.M. and Chen, R.Y. (2013) The Effects of Exercise Program on Burnout and Metabolic Syndrome Components in Banking and Insurance Workers. Industrial Health, 51, 336-346.

https://doi.org/10.2486/indhealth.2012-0188 


\section{Survey Sheet}

\section{BURNOUT OR PROFESSIONAL EXHAUSTION SYNDROME AMONG HEALTH CARE PERSONNEL IN COTONOU HOSPITAL}

Hello Mr/Mrs. This work has been authorized by the hospital authorities and will be carried out in strict confidentiality and with respect for the anonymity of the participants.

Signature of participant Date.

Identity: Telephone:

\section{Socio-professional data}

Q1) Sex: 1. male / / 2. Female /

Q2) Age:

$$
\text { Caregiver Other (Please specify.. }
$$
/ Midwife/ / Doctor/ / Surgeon

Q4) Marital status: Single /__ / Married/ / Cohabiting / / Divorced/ / Widowed /

Q5) Number of dependent children: /__ / None $\left.[1-3] / \_/ 4-6\right] / \_/ \geq 7 / \_/$

Q6) What department are you in?:

Q7) How long have you been in the profession: $<1$ year /__ / $[1-5$ years $] /[/$ $[6-10$ years $] /\left[/[11-20\right.$ years $] / \_/>20$ years $/$

Q8) Work schedule: Fixed schedule (8 am to $4 \mathrm{pm})$ Alternating schedule (duty $\{8$ am to $4 \mathrm{pm}\} /$ and on-call $\{4 \mathrm{pm}$ to $8 \mathrm{am}\}) /$

Q9) Average number of hours worked per week: $<40$ hours /__ / [40 and 72 hours $] / \_/>72$ hours /

Q10) How many night shifts do you work per month?:

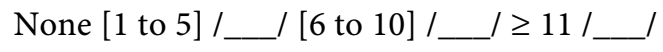

Q11) Average number of weeks of vacation per year?: [ 1 to 2 weeks] /__ / [3 to 4 weeks] /__/ $>5$ weeks/

Q12) Do you feel that you spend enough time with your family? Yes /__ / No /

Q13) Do you receive negative comments from family or friends about your availability? Yes / / No/

Q14) Do you participate in any regular sports activities? Yes/ / No /

Q15) Do you have a regular leisure activity? Yes / / No /

Q16) How do you rate the work climate in your department? Very good Good Bad Very bad

\section{History}

Q17) Do you have high blood pressure: Yes/__ / No /__ /

Q18) Do you drink alcohol (beer, wine, soda, whiskey, vodka)? 
Yes / / No /

If yes: glasses per week or. glasses per day?

Q19) Do you smoke? Yes/ / No /

- If yes: .cigarettes per day for.......years

Q20) Have you used psychotropic drugs (antidepressants, anti-anxiety drugs or sleeping pills) in the last three months? Yes / / No /

\section{The Maslach Burnout Inventory}

How do you perceive your work? Are you exhausted? How capable are you of shaping your relationship to others? To what degree are you personally fulfilled? Indicate how frequently the following statements apply to you and add the points indicated on top of the respective box:

$$
\begin{aligned}
& 0=\text { Never } \\
& 1=\text { At least a few times a year } \\
& 2=\text { At least once a month } \\
& 3=\text { Several times a month } \\
& 4=\text { Once a week } \\
& 5=\text { Several times a week } \\
& 6=\text { Every day }
\end{aligned}
$$

\begin{tabular}{llllll}
\hline & 5 & 0 & 1 & 2 & 3
\end{tabular}

01) I feel emotionally exhausted because of my work

02) I feel worn out at the end of a working day

03) I feel tired as soon as I get up in the morning and see a new working day stretched out in front of me

04) I can easily understand the actions of my colleagues/supervisors

05) I get the feeling that I treat some clients/colleagues impersonally, as if they were objects

06) Working with people the whole day is stressful for me

07) I deal with other people's problems successfully

08) I feel burned out because of my work

09) I feel that I influence other people positively through my work

10) I have become more callous to people since I have started doing this job

11) I'm afraid that my work makes me emotionally harder

12) I feel full of energy

13) I feel frustrated by my work

14) I get the feeling that I work too hard

15) I'm not really interested in what is going on with many of my colleagues

16) Being in direct contact with people at work is too stressful

17) I find it easy to build a relaxed atmosphere in my working environment

18) I feel stimulated when I been working closely with my colleagues

19) I have achieved many rewarding objectives in my work

20) I feel as if I'm at my wits' end

21) In my work I am very relaxed when dealing with emotional problems

22) I have the feeling that my colleagues blame me for some of their problems 